\title{
Research on Evaluation and Early-warning of Regional Ecological Security Based on NC-AHP
}

\author{
DONG Huizhong ${ }^{1, a}$, WU Peng ${ }^{1, b}$, WU Zongjie ${ }^{1, c}$, Jiang Bing ${ }^{1, d}$, Xing \\ Tongwei ${ }^{1, \mathrm{e}}$ \\ ${ }^{1}$ School of business, Shandong University of Technology, Shandong Zibo 255012, China \\ asdutdhz@126.com, ${ }^{b} 18463090150 @ 163 . c o m,{ }^{c}$ wzj@sdut.edu.cn, ${ }^{d} 15169268161 @ 163 . c o m$, \\ esdlgskc@163.com
}

\begin{abstract}
Keywords: normal cloud, regional ecological security, early-warning model, the efficient ecological economic zone of the Yellow River Delta

Abstract. In view of the problems of the randomness and fuzziness that in the process of the evolution of ecological security, in this paper, proposed a comprehensive analysis model based on NC (normal cloud) -AHP. The regional ecological security index system was constructed based on the ecosystem state, ecosystem danger and ecosystem immunity. The model was employed to quantitatively assess and dynamically early-warning the ecological security of the efficient ecological economic zone of the Yellow River Delta during the historical years (2003 2013) and the year of planning (2016). The results show that: the ecological security status from "danger" state to "sensitive" state to "good" state from 2003 2013, which demonstrate that the overall status of ecological security is undergoing increasing improvement, but all safety states are less than the general requirement of "safe" state. In 2016, the regional ecological security will be "good" state and has the tendency of developing to "sensitive" state. Atmospheric pollution, water resources shortage, energy consumption and industrial "three wastes" are the mainly short board factors of ecological environment in the efficient ecological economic zone of the Yellow River Delta.
\end{abstract}

\section{Introduction}

Regional ecological security refers to the inner function, structure and external performance of regional ecological system in a certain time and space. Under the positive response of the dual pressures of social economy and natural environment and human activities it provided for social and economic stability and human health development the ecological support and impact, so that the health of human society, development, production and life is not a threat to the state [1]. The accurate identification of ecological security can help to correctly grasp the health status of the ecosystem and provide scientific basis for regional planning and development. It has important guiding significance to the sustainable and healthy development of regional social system, economic system and ecological environment system [2]. At present, with the rapid development of economic society and the rapid expansion of population, the regional ecological security situation is grim and the ecological problems highlighted, the ecological security has become a hot spot for the government and academia [3]. At present, domestic and foreign scholars on the study of ecological security can be divided into the following aspects: the concept of definition [4], theoretical identification [5], and evaluation index system to build [6], ecological security evaluation and early warning [7], ecological carrying capacity analysis [8], landscape pattern analysis [9] and countermeasures [10] and so on. As one of the important contents of ecological security, ecological security early warning is the prediction, evaluation and warning of the regional ecological environment and the coordinated development of social economy and ecological environment so that achieve the improvement and control of adverse factors [11]. The common methods for early warning of ecological security are fuzzy matter element evaluation, artificial neural network and system dynamics and so on. Fuzzy matter element evaluation method [12] reflects the fuzzy nature of the evaluation object and the actual situation of the evaluation object but it relied over on the effect of extreme value which resulted in more information loss and the lack of reliability of the index weight. The advantage of artificial neural network [13] is to find the minimum error corresponding to the grid parameters, but it can be found in local minimum. System dynamics [14] 
has the advantages of both information theory and control theory. It has advantages in dealing with the problem of dealing with periodicity and long time. However, the method has a significant difference in the different models and the final results of the same problem. Therefore, the existing early warning model has some limitations in reflecting such as the multi factor, multi dimension and dynamic adaptability of regional ecological security.

Based on NC-AHP theory and by introducing normal cloud into regional ecological security warning, the problem of stochastic and fuzzy in regional ecological security early warning is solved. Taking the Yellow River delta efficient ecological economic zone as an example, based on the concept model of "State-Danger-Immunity, SDI" constructed the early warning index system of high efficient ecological economic zone in the Yellow River delta and made an evaluation of the ecological security level in the time scale (2003 2013) to carry out early warning of the regional ecological security development trend in 2016.

\section{Research methods}

\section{Research on early-warning of regional ecological security based on NC-AHP}

This paper constructs the comprehensive early warning model which is based on the NC-AHP, the main steps of the model construction are as follows:

Step1: Establishing target domain of early warning objects $U=\left\{u_{1}, u_{2}, u_{3}, \mathrm{~L}, u_{n}\right\}$, early warning domain $V=\left\{v_{1}, v_{2}, v_{3}, \mathrm{~L}, v_{n}\right\}$, weight set $W=\left\{w_{1}, w_{2}, w_{3}, \mathrm{~L}, w_{n}\right\}$.

Step2: Establishing fuzzy judgment matrix $R$, which can be used to judge each early warning indexes. The element $r_{i j}$, which is included in matrix $R$, represents the membership that the ith element $u_{i}$ for the $\mathrm{jth}$ safety level. If the membership's upper and lower boundary values respectively is $x_{i j}^{1} 、 x_{i j}^{2}$, then the qualitative concept that element $i$ belongs to safety level $j$ can be expressed through cloud model as follow:

$$
E x_{i j}=\left(x_{i j}^{1}+x_{i j}^{2}\right) / 2
$$

In the division of ecological security early warning level, early warning boundary in early warning domain $V$ belongs to adjacent two safety levels, so boundary membership value should correspondingly belong to two critical safety intervals, which has a certain fuzziness. Therefore can be expressed as follows:

$$
\begin{aligned}
& \exp \left[-\frac{\left(x_{i j}^{1}-x_{i j}^{2}\right)^{2}}{8\left(E n_{i j}\right)^{2}}\right]=0.5 \\
& E n_{i j}=\frac{x_{i j}^{1}-x_{i j}^{2}}{2.355}
\end{aligned}
$$

Step3: Establishing rule base of early warning index (A) and early warning score (B). Let the quantitative value of each early warning index as input value, through the cloud generator $X$, we can get a set of $C G A\left(x_{i}\right)$. Through repeatedly execute positive cloud generator, we can improve the confidence level of the results of early warning. Then, let the weighted average value of calculated value as input value, through the cloud generator $Y$, we can get a set of $C G B\left(y_{i}\right)$. Similarly, through repeatedly execute positive cloud generator, we obtain the weighted average value of $C G B\left(y_{i}\right)$, this value is the quantitative score of single early warning index, as shown in figure 1. 


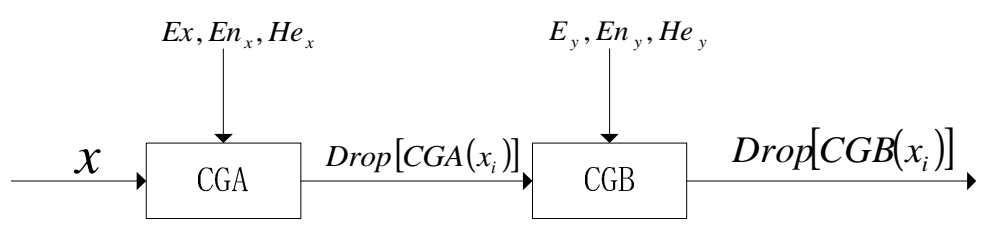

Note: $x$ represents input data, $C G A$ represents data set of cloud $x, E x, E n_{x}, H e_{x}$ separately represents expectation, entropy and hyper entropy of cloud $x ; C G B$ represents data set of cloud $y, E y, E n_{y}, H e_{y}$ separately represents expectation, entropy and hyper entropy of cloud $y$.

Figure1 Cloud model reasoning

Step4: The weight set ( $W$ ) of early warning index is target domain's $(U)$ fuzzy subset, through membership conversion between $W$ and $R$, we can get the membership subset $(B)$, which belongs to early warning domain $(V)$.

$$
B=W \otimes R=\left(b_{1}, b_{2}, b_{3}, \mathrm{~L}, b_{m}\right)
$$

Where $b_{j}=\sum_{i=1}^{n} w_{i} r_{i j}, j=1,2,3, \mathrm{~L}, m ;$ it represents membership that early warning objects belong to the jth safety level. According to the principle of maximum membership, we can select the corresponding early warning level as the security alert level in the research area.

\section{Ecological security early warning in the efficient ecological economic zone of the Yellow River Delta}

\section{Overview of research area}

The Yellow River delta is located in the east longitude $118^{\circ} 30^{\prime} \sim 119^{\circ} 20^{\prime}$, north latitude $37^{\circ} 35^{\prime} \sim 38^{\circ} 10^{\prime}$, including Shandong province's Binzhou, Dongying and partial area of Dezhou, Yantai, Zibo, involving 19 counties (City and district), total area is $2.65 \times 10^{4} \mathrm{~km}^{2}$. Natural disasters occurred frequently in the region, ecological environment is extremely fragile. Especially in recent years, human social activities are becoming increasingly fierce, which bring serious negative impact on the local ecological environment, ecological environment has been severely damaged; leading to ecosystem is more vulnerable. Therefore, objectively to evaluate the ecological security status of Yellow River Delta and scientifically predict regional ecological security trend, it's conducive to enhance regional sustainable development capacity and achieve coordinated and orderly development of economy, society and environment in the Yellow River delta.

\section{Research scales and data sources}

The research scale of this paper is divided into two parts. Firstly, evaluating the ecological security level in the efficient ecological economic zone of the Yellow River Delta from 2003 to 2013, evaluation results can be used to verify the validity of NC-AHP early warning model. Secondly, through the model, we can analyze the ecological security level and development trend of the Yellow River Delta Economic Zone in 2016.

Raw data are mainly derived from Statistical yearbook of Shandong Province (2003 2014), China Statistical Yearbook (2003 2014), Shandong provincial environmental Bulletin (2003 2014), Bulletin of water resources in Shandong Province (2003 2014) and six city's (include Binzhou, Dongying, Yantai, Dezhou, and Zibo) Statistical yearbook (2003 2014) etc.

\section{Establish regional ecological security early warning index system}

Drawing lessons from domestic and foreign related research results and combining the situation of ecological security in the region and the availability of early warning index data, we can establish the regional ecological security early warning index system, which is based on ecological environment state, ecological security stress and ecological risk immunization, as well as it is composed by 22 early warning indexes, as shown in table 1 . Early warning indexes are divided into positive and negative indicators (If the index value is larger and the changing leads to the higher the 
level of regional ecological security as well as the stronger the ability of resisting ecological damage and recover renewable, then the index is a positive index; on the contrary, if the index value is larger and the changing leads to the lower the level of regional ecological security, the greater the ecological pressure, ecological structure becomes more incomplete and functional degradation, then the index is a negative index).

Tab.1 The index system of ecological security Early-warning in the efficient ecological economic zone of the Yellow River Delta

\begin{tabular}{|c|c|c|c|c|c|c|c|c|}
\hline $\begin{array}{l}\text { Target } \\
\text { Layer }\end{array}$ & $\begin{array}{c}\text { Standard } \\
\text { Layer }\end{array}$ & Index Layer & $\begin{array}{c}\text { Red } \\
\text { Alert }\end{array}$ & $\begin{array}{c}\text { Orange } \\
\text { Alert }\end{array}$ & $\begin{array}{r}\text { Yellow } \\
\text { Alert } \\
\end{array}$ & $\begin{array}{l}\text { Blue } \\
\text { Alert }\end{array}$ & $\begin{array}{l}\text { Green } \\
\text { Alert }\end{array}$ & $\begin{array}{c}\text { Index } \\
\text { Weight }\end{array}$ \\
\hline \multirow{21}{*}{ 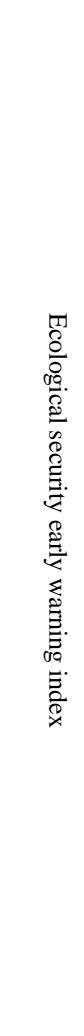 } & \multirow{8}{*}{ 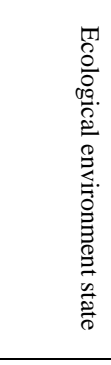 } & Atmospheric environmental index $c_{1}$ & {$[1,0.08]$} & $(0.08,0.06]$ & $(0.06,0.04]$ & $(0.04,0.02]$ & $(0.02,0]$ & 0.0671 \\
\hline & & Water environment index $c_{2}$ & {$[1,0.08]$} & $(0.08,0.06]$ & $(0.06,0.04]$ & $(0.04,0.02]$ & $(0.02,0]$ & 0.0622 \\
\hline & & Per capita arable land $c_{3}$ & {$[0.2,0.5)$} & {$[0.5,0.8)$} & {$[0.8,1.0)$} & {$[1.0,2.0)$} & {$[2.0,3.0]$} & 0.0254 \\
\hline & & Per capita forest area $c_{4}$ & {$[0.5,1.1)$} & {$[1.1,2.5)$} & {$[2.5,4.0)$} & {$[4.0,6.4)$} & {$[6.4,8.0]$} & 0.0453 \\
\hline & & Per capita water resources $c_{5}$ & {$[100,200)$} & {$[200,300)$} & {$[300,600)$} & {$[600,1000)$} & {$[1000,1500]$} & 0.0533 \\
\hline & & Per capita GDP $c_{6}$ & {$[0.6,1.0)$} & {$[1.0,3.5)$} & {$[3.5,6.0)$} & {$[6.0,8.0)$} & {$[8.0,10.0]$} & 0.0505 \\
\hline & & Engel coefficient $\boldsymbol{C}_{7}$ & {$[60,50]$} & $(50,40]$ & $(40,30]$ & $(30,25]$ & $(25,15]$ & 0.0282 \\
\hline & & Three production proportion $c_{8}$ & {$[10,15)$} & {$[15,25)$} & {$[25,35)$} & {$[35,45)$} & {$[45,55]$} & 0.0591 \\
\hline & \multirow{7}{*}{ 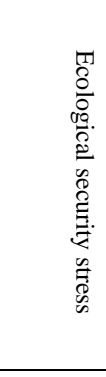 } & Population density $c_{9}$ & {$[800,600]$} & $(600,500]$ & $(500,400]$ & $(400,300]$ & $(300,150]$ & 0.0323 \\
\hline & & Per capita water consumption $c_{10}$ & {$[1200,800]$} & $(800,600]$ & $(600,400]$ & $(400,200]$ & $(200,100]$ & 0.0359 \\
\hline & & Per capita energy consumption $c_{11}$ & {$[4,3]$} & $(3,2.5]$ & $(2.5,1.5]$ & $(1.5,0.5]$ & $(0.5,0]$ & 0.0398 \\
\hline & & Per capita emissions $c_{13}$ & {$[5.0,4.0]$} & $(4 \cdot 0,3.0]$ & $(3.0,2.0]$ & $(2.0,1.0]$ & $(1.0,0.0]$ & 0.0413 \\
\hline & & GDP growth rate $c_{14}$ & {$[25,20]$} & $(20,15]$ & $(15,10]$ & $(10,8]$ & $(8,6]$ & 0.0358 \\
\hline & & Urbanization rate $c_{15}$ & {$[80,70)$} & {$[70,55)$} & {$[55,40)$} & {$[40,30)$} & {$[30,15]$} & 0.0614 \\
\hline & & Forest coverage $c_{16}$ & {$[5,10)$} & {$[10,15)$} & {$[15,25)$} & {$[25,35)$} & {$[35,45]$} & 0.0665 \\
\hline & \multirow{6}{*}{ 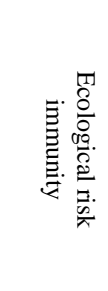 } & Educational input intensity $c_{17}$ & {$[0,0.005)$} & {$[0.005,0.01)$} & {$[0.01,0.015)$} & {$[0.015,0.02)$} & {$[0.02,0.03]$} & 0.0251 \\
\hline & & Technology input intensity $c_{18}$ & {$[0,0.5)$} & {$[0.5,1.0)$} & {$[1.0,1.5)$} & {$[1.5,2)$} & {$[2,2.5]$} & 0.0318 \\
\hline & & Environmental input intensity $c_{19}$ & {$[0,0.002)$} & {$[0.002,0.004)$} & {$[0.004,0.006)$} & {$[0.006,0.008)$} & {$[0.008,0.01]$} & 0.0391 \\
\hline & & Industrial solid waste utilization rate $c_{20}$ & {$[20,45)$} & {$[45,50)$} & {$[50,60)$} & {$[60,70)$} & {$[70,95]$} & 0.0454 \\
\hline & & Industrial waste gas treatment rate $c_{21}$ & {$[20,40)$} & {$[40,50)$} & {$[50,60)$} & {$[60,70)$} & {$[70,95]$} & 0.0546 \\
\hline & & Industrial wastewater discharge rate $c_{22}$ & {$[20,40)$} & {$[40,55)$} & {$[55,75)$} & {$[75,95)$} & {$[95,100]$} & 0.058 \\
\hline
\end{tabular}

\section{Early warning classification}

Referencing to the research results of existing ecological security assessment, the ecological security level is divided into five grades. From inferior to superior, we can divide the ecological security level into: I(Deterioration state), II(Dangerous state), III(Sensitive state), IV(Good state), $\mathrm{V}$ (Safe state), the early warning process of regional ecological security can be expressed as a set $S$ : $S=\{$ Deterioration $\rightarrow$ Dangerous $\rightarrow$ Sensitive $\rightarrow$ Good $\rightarrow$ Safe $\}, I=\{$ Safe $\}, I I=\{$ Good $\}, I I I=\{$ Sensitive $\}$, $\mathrm{IV}=\{$ Dangerous $\}, \mathrm{V}=\{$ Deterioration $\}$. Among them, I, II, III, IV, V $\in s$ and $\forall s \in S$, the specific contents of each ecological security level is shown in table 2 . 
Tab.2 Criterion of regional ecological security classification

\begin{tabular}{|c|c|c|c|}
\hline $\begin{array}{l}\text { Safety } \\
\text { Level }\end{array}$ & Feature State & Features of early warning level & $\begin{array}{c}\text { Safety } \\
\text { Warning }\end{array}$ \\
\hline I & Safe state & $\begin{array}{l}\text { The ecosystem's structure is complete, function is good, the ability of } \\
\text { resisting ecological damage and recover renewable is strong, do not } \\
\text { have obvious ecological forcing factors and the system of environment } \\
\text { and resources protection is perfect. }\end{array}$ & $\begin{array}{l}\text { Green } \\
\text { Alert }\end{array}$ \\
\hline II & Good state & $\begin{array}{l}\text { Ecological environment is less affected by external interference and } \\
\text { can bear part of the damage, ecosystem's function and structure is } \\
\text { complete, high degree of response of management of environmental } \\
\text { resources, environmental problems are rarely occur. }\end{array}$ & $\begin{array}{l}\text { Blue } \\
\text { Alert }\end{array}$ \\
\hline III & Sensitive state & $\begin{array}{l}\text { Ecological environment is disturbed by external factors, ecosystem's } \\
\text { function began to degenerate and structure began to deteriorate, } \\
\text { ecological problems are gradually highlight, ecological disasters } \\
\text { happen occasionally, lacking of resources and environment's } \\
\text { management. }\end{array}$ & $\begin{array}{l}\text { Yellow } \\
\text { Alert }\end{array}$ \\
\hline IV & $\begin{array}{l}\text { Dangerous } \\
\text { state }\end{array}$ & $\begin{array}{l}\text { Ecological environment is seriously affected by the outside } \\
\text { interference, ecosystem lose partial function, structure deteriorate } \\
\text { badly, ecological environment problems are serious, resources and } \\
\text { environment's protection policies are not reasonable enough. }\end{array}$ & $\begin{array}{c}\text { Orange } \\
\text { Alert }\end{array}$ \\
\hline V & $\begin{array}{l}\text { Deterioration } \\
\text { state }\end{array}$ & $\begin{array}{l}\text { Ecological environment has been destroyed seriously, the structure and } \\
\text { function of ecological system are incomplete, it is difficult to recover } \\
\text { and rebuild after being destroyed, natural disasters occur frequently, the } \\
\text { protection of resources and environment is seriously lagging behind. }\end{array}$ & $\begin{array}{l}\text { Red } \\
\text { Alert }\end{array}$ \\
\hline
\end{tabular}

\section{Determine threshold value of index and NC digital features}

\section{The threshold value of early warning index}

Referencing to the provisions of the national ecological quality standards and the background standards of local environmental quality, combining with the historical statistics (2003 2013) of the Yellow River Delta Economic Zone, according to the principles of locality, operability and systemic, marking off the threshold intervals that each early warning index correspond to different security levels (as shown in table 1).

\section{Digital features of normal cloud}

According to formulas from (2) to (4), the threshold intervals that each early warning index corresponds to different security levels can be represented by normal cloud. Taking the normal cloud standards of the ecological security early warning indexes into positive normal cloud generator, we can get normal clouds that each early warning index corresponds to different security levels. Taking influencing factors - population density $\left(c_{9}\right)$ as an example, we can form the membership function of standard normal cloud (as shown in figure 2).

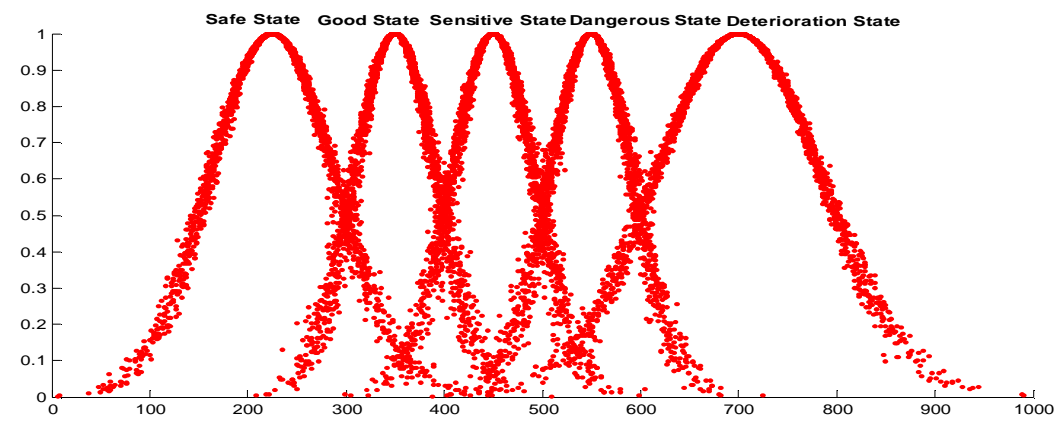

Figure 2 Normal cloud membership of population density

\section{Calculation and interpretation of result}

\section{Analysis of the ecological level from 2003 to 2013}

Calculating the fuzzy set $\hat{\phi}$ on the comment set $G$ base on index weight set $W$ and membership matrix $\hat{\xi}=\left(\xi_{i j}\right)_{n \times m}$. That mean the membership degree of ecological level corresponds 
to which safety grade in different years. According to $\hat{\phi}_{j 0}=\max _{j \in\{\mathrm{II}, \mathrm{II}, \mathrm{L}, \mathrm{V}\}} \phi_{j}$, we can get the ecological security level of every year (as shown in table 3 ).

From the result of model calculation, the ecological security in the zone of the Yellow River Delta transformed from "Danger" state to "sensitive" state and then turned to "good" state. The ecological security level presents a trend of gradually improving. From 2003 to 2005, the ecological environment of the Yellow River Delta economic zone was in the "dangerous" state, which showed the level of ecological security was low. By 2006 $\left(\phi_{2006}(j)=\max _{j \in\{I, I I, I I I, I V, V\}} \phi_{2006}(j)=\phi_{2006}(\mathrm{III})=0.33526>0\right)$, Ecological security reached to the "sensitive" state and achieved a key breakthrough from "danger" state to "sensitive" state. From 2006 to 2011, the maximum subordinate degree of ecological security in the Yellow River Delta economic zone was in the III range, which indicated ecological environment was in the "sensitive" state. By $2012\left(\phi_{2012}(j)=\max _{j \in\{\mathrm{I}, \mathrm{II}, \mathrm{III}, \mathrm{IV}, \mathrm{V}\}} \phi_{2012}(j)=\phi_{2012}(\mathrm{II})=0.34259>0\right)$, ecological security reached to the "good" state and achieved a key breakthrough again that from "sensitive" state to "good" state. In 2013, the ecological environment of the economic zone was in the "good" state $\left(\phi_{2013}(j)=\max _{j \in\{\mathrm{I}, \mathrm{II}, \mathrm{III}, \mathrm{IV}, \mathrm{V}\}} \phi_{2013}(j)=\phi_{2013}(\mathrm{II})=0.37717>0\right)$ meanwhile it had the tendency of developing to the "sensitive" state $\left(\phi_{2013}(\mathrm{I})=0.15713<\phi_{2013}(\mathrm{III})=0.27620\right)$.

Tab.3 Integrated assessment results of regional ecological security in the efficient ecological economic zone of the Yellow River Delta

\begin{tabular}{|c|c|c|c|c|c|c|c|}
\hline Safety Level & $\begin{array}{c}\text { Safe State } \\
\text { (I) }\end{array}$ & $\begin{array}{l}\text { Good State } \\
\text { (II) }\end{array}$ & $\begin{array}{c}\text { Sensitive State } \\
\text { (III) }\end{array}$ & $\begin{array}{l}\text { Dangerous } \\
\text { State (IV) }\end{array}$ & $\begin{array}{l}\text { Deterioration } \\
\text { State (V) }\end{array}$ & $\begin{array}{c}\text { Security } \\
\text { Level }\end{array}$ & $\begin{array}{c}\text { Changing } \\
\text { Trend }\end{array}$ \\
\hline$\phi_{2003}$ & 0.08847 & 0.18375 & 0.26872 & 0.32440 & 0.11715 & IV & III \\
\hline$\phi_{2004}$ & 0.09534 & 0.18481 & 0.28988 & 0.32487 & 0.09861 & IV & III \\
\hline$\phi_{2005}$ & 0.08915 & 0.19020 & 0.31116 & 0.31729 & 0.09737 & IV & III \\
\hline$\phi_{2006}$ & 0.09847 & 0.21536 & 0.33526 & 0.26035 & 0.09045 & III & II \\
\hline$\phi_{2007}$ & 0.12826 & 0.24516 & 0.34438 & 0.18367 & 0.09640 & III & II \\
\hline$\phi_{2008}$ & 0.11119 & 0.13372 & 0.38880 & 0.27484 & 0.08453 & III & IV \\
\hline$\phi_{2009}$ & 0.14697 & 0.28203 & 0.38493 & 0.10401 & 0.07463 & III & II \\
\hline$\phi_{2010}$ & 0.11123 & 0.30324 & 0.36715 & 0.11362 & 0.09113 & III & II \\
\hline$\phi_{2011}$ & 0.11238 & 0.32165 & 0.35890 & 0.09789 & 0.09767 & III & II \\
\hline$\phi_{2012}$ & 0.13406 & 0.34259 & 0.32198 & 0.09737 & 0.08233 & II & III \\
\hline$\phi_{2013}$ & 0.15713 & 0.37717 & 0.27620 & 0.09444 & 0.07922 & II & III \\
\hline
\end{tabular}

According to the development and change show that the economic zone of the Yellow River Delta has got remarkable results in the ecological protection and governance in recent years, so the problem of regional ecological security was effectively controlled. But through the perspective of the membership degree of ecological security, the regional ecological security situation is still not optimistic and the level of security is under "safe" state. The results are consistent with the reality of the efficient ecological economic zone of the Yellow River Delta, which shows the regional ecological security early warning model (NC - AHP) is reliable and reasonable.

\section{Ecological security warning in 2016}

Through the grey model, we get the value of early warning index in 2016 and then take it into the NC-AHP model; we can obtain the results of the regional ecological security early warning in 2016 (as shown in table 4).

On the one hand, from the result $\left(\hat{\varphi}_{2016}=\max _{j=\{I, I I, L, V\}} \varphi_{2016}=I I=0.39702\right)$ we can know the ecological security of the Yellow River Delta Economic Zone will belong to grade II (namely "good" state) in 2016. On the other hand, $\varphi_{2016}(\mathrm{I})=0.15442, \varphi_{2016}(\mathrm{III})=0.25332$ and $\varphi_{2016}(\mathrm{I})<\varphi_{2016}(\mathrm{III})$, which shows the ecological security has a degraded tendency to "sensitive" 
state. The changing trend of ecological security is still grim, so we have to pay more attention to the ecological security.

Tab.4 Integrated assessment results of regional ecological security in the efficient ecological economic zone of the Yellow River Delta

\begin{tabular}{|c|c|c|c|c|c|c|c|}
\hline$\underbrace{\text { Safety Level }}_{\text {Evaluation Value }}$ & $\begin{array}{l}\text { Safe State } \\
\text { (I) }\end{array}$ & $\begin{array}{l}\text { Good State } \\
\text { (II) }\end{array}$ & $\begin{array}{l}\text { Sensitive State } \\
\text { (III) }\end{array}$ & $\begin{array}{l}\text { Dangerous State } \\
\text { (IV) }\end{array}$ & $\begin{array}{l}\text { Deterioration State } \\
\text { (V) }\end{array}$ & $\begin{array}{c}\text { Security } \\
\text { Level }\end{array}$ & $\begin{array}{l}\text { Changing } \\
\text { Trend }\end{array}$ \\
\hline$\varphi_{i}\left(c_{1}\right)$ & 0.00437 & 0.01249 & 0.01596 & 0.01345 & 0.00552 & III & IV \\
\hline$\varphi_{j}\left(c_{2}\right)$ & 0.00411 & 0.01107 & 0.01787 & 0.01126 & 0.00611 & III & IV \\
\hline$\varphi_{i}\left(c_{3}\right)$ & 0.00821 & 0.02274 & $3.94 \mathrm{E}-07$ & $5.21 \mathrm{E}-08$ & $1.8 \mathrm{E}-14$ & II & I \\
\hline$\varphi_{i}\left(c_{4}\right)$ & 2.36E-10 & 0.00443 & 0.04197 & 0.00573 & 4.34E-05 & III & IV \\
\hline$\varphi_{i}\left(c_{5}\right)$ & $2.06 \mathrm{E}-12$ & 0.00021 & 0.01705 & 0.04068 & $1.03 \mathrm{E}-20$ & IV & III \\
\hline$\varphi_{i}\left(c_{6}\right)$ & 0.00154 & 0.04848 & 0.00847 & $6.2 \mathrm{E}-06$ & 0 & II & III \\
\hline$\varphi_{i}\left(c_{7}\right)$ & 0.00044 & 0.00231 & 0.02286 & 0.00031 & $1.01 \mathrm{E}-11$ & III & II \\
\hline$\varphi_{i}\left(c_{8}\right)$ & 0.00528 & 0.05840 & 0.00255 & $4.38 \mathrm{E}-07$ & $1.74 \mathrm{E}-11$ & II & I \\
\hline$\varphi_{i}\left(c_{9}\right)$ & 0.00551 & 0.03206 & 0.00151 & $2.76 \mathrm{E}-07$ & $2.08 \mathrm{E}-17$ & II & I \\
\hline$\varphi_{j}\left(c_{10}\right)$ & $8.47 \mathrm{E}-10$ & 0.01754 & 0.01836 & $7.51 \mathrm{E}-05$ & $7.25 \mathrm{E}-05$ & III & II \\
\hline$\varphi_{j}\left(c_{11}\right)$ & 0.00021 & 0.00357 & 0.00988 & 0.01334 & 0.03816 & IV & III \\
\hline$\varphi_{i}\left(c_{12}\right)$ & $2.16 \mathrm{E}-37$ & $8.14 \mathrm{E}-26$ & $6.84 \mathrm{E}-10$ & $2.31 \mathrm{E}-09$ & $1.19 \mathrm{E}-16$ & III & IV \\
\hline$\varphi_{i}\left(\mathrm{c}_{13}\right)$ & $1.2 \mathrm{E}-18$ & $6.46 \mathrm{E}-11$ & $1.33 \mathrm{E}-05$ & 0.01057 & 0.03215 & V & IV \\
\hline$\varphi_{i}\left(c_{14}\right)$ & 0.00992 & 0.00019 & $1.42 \mathrm{E}-05$ & $5.98 \mathrm{E}-09$ & $7.23 \mathrm{E}-16$ & I & II \\
\hline$\varphi_{i}\left(c_{15}\right)$ & 0.00011 & 0.00329 & 0.05775 & 0.00158 & $1.39 \mathrm{E}-12$ & III & II \\
\hline$\varphi_{j}\left(c_{16}\right)$ & 0.02382 & 0.04347 & 0.00031 & $1.99 \mathrm{E}-07$ & $2.62 \mathrm{E}-10$ & II & I \\
\hline$\varphi_{j}\left(c_{17}\right)$ & $1.41 \mathrm{E}-06$ & $3.52 \mathrm{E}-06$ & 0.00394 & 0.02128 & 0.00022 & IV & III \\
\hline$\varphi_{i}\left(c_{18}\right)$ & 0.00089 & 0.03026 & 0.00395 & $1.98 \mathrm{E}-06$ & $3.8 \mathrm{E}-12$ & II & III \\
\hline$\varphi_{j}\left(c_{19}\right)$ & 0.01269 & 0.02372 & $1.31 \mathrm{E}-05$ & $2.62 \mathrm{E}-11$ & $1.01 \mathrm{E}-19$ & II & I \\
\hline$\varphi_{i}\left(c_{20}\right)$ & 0.02064 & 0.00067 & $2.79 \mathrm{E}-05$ & $1.43 \mathrm{E}-06$ & $8.49 \mathrm{E}-10$ & I & II \\
\hline$\varphi_{i}\left(c_{21}\right)$ & 7.95E-12 & 0.05163 & 0.00709 & $3.8 \mathrm{E}-06$ & 0.00147 & II & III \\
\hline$\varphi_{i}\left(c_{22}\right)$ & 0.05651 & 0.01366 & $1.55 \mathrm{E}-05$ & $2.1 \mathrm{E}-16$ & $1.75 \mathrm{E}-16$ & I & II \\
\hline$\phi_{2016}$ & 0.15442 & 0.39702 & 0.25322 & 0.08375 & 0.07760 & II & III \\
\hline
\end{tabular}

From the result of early warning, we know the main factors that limit the promotion of the ecological level is: water environment index, forest coverage, per capita energy consumption, per capita emissions, educational input intensity, per capita forest area, per capita water resources, urbanization rate and per capita sewage discharge. Among them, per capita water resources $\left(\max _{j \in\{\mathrm{II}, \mathrm{I}, \mathrm{L}, \mathrm{V}\}} \varphi_{j}\left(c_{4}\right)=\mathrm{IV}=0.04068\right)$, per capita energy consumption $\left(\max _{j \in\{\mathrm{IIII}, \mathrm{L}, \mathrm{V}\}} \varphi_{j}\left(c_{11}\right)=\mathrm{IV}=0.01334\right)$, per capita emissions ( $\left.\max _{j \in\{\mathrm{I}, \mathrm{II}, \mathrm{L}, \mathrm{V}\}} \varphi_{j}\left(c_{13}\right)=\mathrm{V}=0.03215\right)$ and educational input intensity $\left(\max _{j \in\{I, I, L, V\}} \varphi_{j}\left(c_{17}\right)=I V=0.02128\right)$ are all in the "dangerous" or "deteriorating" state, which serious constraints regional ecological change into the "safe" state.

Therefore, on the one hand, we should take the short board factors as the focus of ecological improvement and control during the protection work of ecological environment in the future; On the other hand, through take active and effective management measures, we can drive the regional ecological security in the efficient ecological economic zone of the Yellow River Delta reaching the "safe" state.

\section{Conclusions}

(1) This paper proposes a new kind of comprehensive early warning analysis model (NC-AHP) and applies it to the quantitative evaluation of ecological environment level in the efficient ecological economic zone of the Yellow River Delta from 2003 to 2013. The results show that the 
ecological environment transformed from "danger" state to "sensitive" state and then turned to "good" state. The ecological security level had been promoted and effectively controlled. However, the overall level of regional ecological security is still low and is under "safe" state. The evaluation results are basically consistent with the regional ecological situation.

(2) Under the implementation of the target environment situation, we carried out early warning on the ecological security of the regional ecological security in the efficient ecological economic zone of the Yellow River Delta in 2016. The results show that the early warning of ecological security is "blue" in 2016 and presents a trend of changing into the "yellow" warning. Shortage of fresh water resources, high per capita energy consumption, lots of capita emissions, forest coverage rate is low, educational input intensity is weak, water environment and atmospheric environment index are all higher are the main factors which restrict the improvement of ecological environment, these aspects needed to focus on improvement and management. The early warning values of three production proportions, population density, investment in technology and environmental protection, industrial solid waste utilization rate and industrial wastewater discharge rate are at "good" or "safe" state, these positive factors promote the continuous improvement of the regional ecological environment.

\section{Acknowledgements}

This work was financially supported by the National Natural Science Foundation of China(71371112), Natural Science Foundation of Shandong Province(ZR2012GM020).

\section{References}

[1] Junhuang Cai. Research progress and Prospect of domestic and international ecological security. Journal of Fujian Party School. 2015; (2): 104-110.

[2] Xiaoli Lu, Xiaonan Qin. A BP-DEMATEL-Model-based research of the factors that affect coastal urban ecological security system. Management Review, 2015; 27(5): 48-57.

[3] McNeil D N, Schweitzer D E. Environmental security: an evolving concept. Environmental Science \& Technology. 2007, 3(5): 108-113.

[4] Ma K M, Fu BJ, Li X Y, Guan W B. The concept and theoretical basis of the regional pattern of ecological security. Acta Ecological Sinica. 2004; 24(4) : 761-768.

[5] Geng Wang, Li Wang, Wei Wu. Recognition on regional ecological security definition and assessment system. Acta Ecological Sinica. 2007; 27(4): 1627-1637.

[6] Yong Liu, Yuzhao Li, Xiaopin Yan. A DPSIR-Based indicator system for ecological security assessment at the Basin Scale. Acta Scientiarum Naturalium Universitatis Pekinensis. 2012; 48(6): 971-981.

[7] Weihong Zhu, Chengyu Miao, Xiaojun Zheng, et al. Study on ecological safety evaluation and warning of wetlands in Tumen River watershed based on 3S technology. Acta Ecologica Sinica. 2014; 34(6): 1379-1390.

[8] Ma K M, Fu BJ, Li X Y, Guan W B. The concept and theoretical basis of the regional pattern of ecological security. Acta Ecologica Sinica. 2004; 24(4) : 761-768.

[9] Yong Huang, Fengyou Wang, Tijiu Cai, et al. Landscape pattern dynamic analysis based on change trajectory method in Bohai rim area. Journal of Soil and Water Conservation. 2015; 29(2): 314-319. 
[10] Pan J H, Feng Z D. Evaluation of eco-environmental fragility in middle reaches of heihe river using information entropy and matter-element model. Journal of Ecology and Rural Environment. 2008; 24( 1) : 1-4.

[11] Qiang Zhang, Mingjun Zhang, Huifeng Xue, et al. Early-warning model based on extension analysis for ecological security and its application: case study of Shaanxi Province. Acta Ecological Sinica. 2010; 30(16): 4277-4286.

[12] Hong Yang, Meizhu Zhang. Evaluation of eco-environmental quality of Caohai Wetland in Weining county based on fuzzy matter-element method. Water Saving Irrigation. 2015; (2): 54-57.

[13] Haitao Zhang, Li Li. Assessment model of townlet eco-environmental quality based on BP-artificial neural net-work. Chinese Journal of Applied Ecology. 2008; 19(12): 2693-2698.

[14] Renjun Xiao, Zhi Dong, Xiuting Li, et al. The system dynamics model of energy sustainable development in Xinjiang. Management Review. 2014; 26(8): 31-41.

[15] GuangWei Zhang, DeYi Li, Peng Li, et al. A collaborative filtering recommendation algorithm based on cloud model. Journal of Software. 2007; 18(10): 2403-2411. 